\title{
A New Simplified Metal Guide for Optimal Microimplant Insertion
}

\author{
${ }^{1}$ Vinayak Shridharrao Kulkarni, ${ }^{2}$ Girish Ramchandra Karandikar, ${ }^{3}$ Amol Chandrakant Mhatre \\ ${ }^{4}$ Shaili Sanjay Shah, ${ }^{5}$ Hitesh Jagdish Burad, ${ }^{6}$ Azeem Sajjad Patel
}

\begin{abstract}
Microimplants have become increasingly popular because they are small and easy to insert and remove, can be loaded immediately after insertion, and do not require patient compliance. They provide absolute skeletal anchorage for various orthodontic treatment modalities.

Precise positioning of microimplants is critical to their success. Insertion too close to adjacent tooth roots increases the risk of implant failure, especially in the mandible. Abnormal placement interferes with planned tooth movements.

Authors have developed a metal guide that can improve the accuracy of microimplant placement in the anterior or posterior segments of either arch. It is easily attached to the archwire and is then disengaged after drilling, without the need for arch wire removal and with no deformation of either the archwire or the guide. Its simple design permits easy fabrication, does not require construction of acrylic surgical stents. The guide can also be resterilized, thus the same one can be used for different patients.
\end{abstract}

Keywords: Microimplant placement guide, Metal guide, Miniscrew insertion.

How to cite this article: Kulkarni VS, Karandikar GR, Mhatre AC, Shah SS, Burad HJ, Patel AS. A New Simplified Metal Guide for Optimal Microimplant Insertion. J Contemp Dent 2014;4(1): 63-65.

Source of support: Nil

Conflict of interest: None

\section{INTRODUCTION}

Temporary anchorage devices (TADs), in the form of miniscrew or microscrew implants, have become an accepted component of the day-to-day orthodontic armamentarium. TADs have become increasingly popular because they are small and easy to insert and remove, they can be loaded immediately after insertion, and they can provide absolute anchorage for various orthodontic treatment modalities, with no need for special patient compliance.

Precise positioning of microimplants is critical to their success. Insertion too close to adjacent tooth roots

\footnotetext{
${ }^{1,4-6}$ Postgraduate Student, ${ }^{2}$ Professor and Guide

${ }^{3}$ Senior Lecturer

${ }^{1-6}$ Department of Orthodontics, MGM Dental College and Hospital, Navi Mumbai, Maharashtra, India
}

Corresponding Author: Vinayak Shridharrao Kulkarni Postgraduate Student, Department of Orthodontics, MGM Dental College and Hospital, Navi Mumbai, Maharashtra India, Phone: 02452225263, e-mail: vinayakkulkar@gmail.com increases the risk of implant failure, especially in the mandible. Poor placement may also interfere with planned tooth movements. ${ }^{1}$

The use of a guidance apparatus can facilitate accurate microimplant placement. Infinitas Mini-implant System ${ }^{\mathrm{TM}}$ is a 3-Dimensional system introduced in $2009,{ }^{2}$ but is complicated, time consuming and expensive. Surgical stents ${ }^{3}$ have also been developed, which are precise. However, they require laboratory fabrication using acrylic and thus need an extra appointment. Also, these have to be customized for every patient.

We have developed a metal guide that can improve the accuracy of microimplant placement in the anterior or posterior segments of either arch. It is easily attached to the archwire to determine the ideal microimplant position and is then disengaged after drilling, without the need for arch wire removal and with no deformation of either the archwire or the guide. It's simple design permits easy fabrication, and as the guide can be re-sterilized,the same one can be used for different patients.

\section{APPLIANCE DESIGN AND FABRICATION}

The microimplant placement guide is fabricated from a straight length, rectangular 0.017 " $\times 0.025$ " stainless steel wire. Adequate length of the wire is cut and bent in the form of a ' $U$ ' (Fig. 1A). Six pieces of $2.5 \mathrm{~mm}$ length wires are cut and welded at a distance of $1.5 \mathrm{~mm}$ to form a ladder like structure (Fig. 1B). Thus, the ladder comprises of 6 rectangles; each of width $2.5 \mathrm{~mm}$ and height $1.5 \mathrm{~mm}$, and the total height being $9 \mathrm{~mm}$. The ends are then bent into hooks which are to be engaged onto the archwire (Fig. 1C). The side view of the completed metal guide is shown in Figure 1D.

This guide can be fabricated in varying lengths of 4.5 , $6,7.5,9,10.5$ and $12 \mathrm{~mm}$ owing to placement in various anatomic regions of the oral cavity. Due to the variation in the width of the attached gingiva and vestibular depths in different patients, this wide a range of lengths shall prove to be a useful aid.

\section{APPLIANCE PLACEMENT}

Initially the microimplant placement area is determined. The guide is then secured over the archwire. This can be 


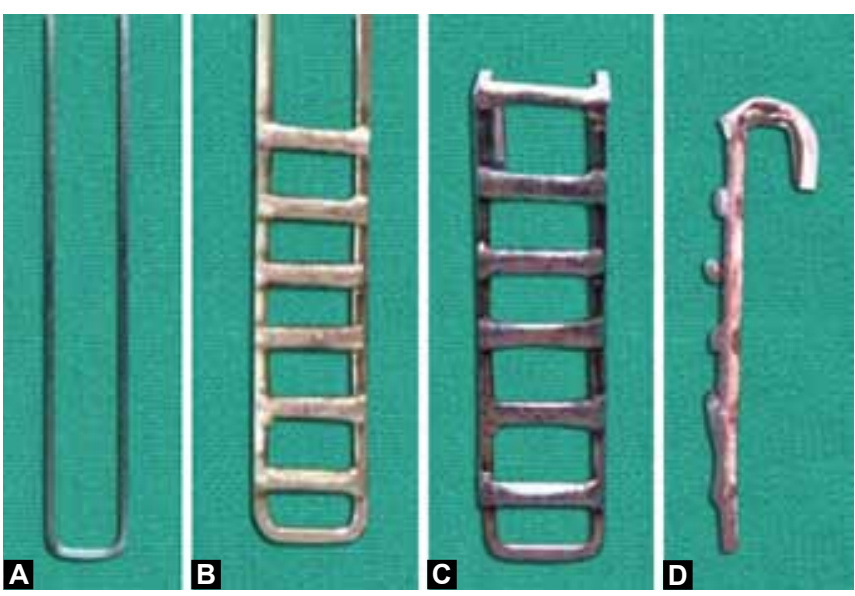

Figs 1A to D: Appliance design and fabrication of the metal microimplant placement guide

done using two methods: either a piece of ligature wire can be wound around the archwire with the guide in place; or a blob of composite resin can be placed connecting the metal guide to the archwire in the desired position.

Once the guide is secured onto the archwire, an intraoral periapical radiograph is taken. Studies show that generally the placement is 5 to $6 \mathrm{~mm}$ apical to the alveolar crest. ${ }^{4}$ The horizontal positioning of the guide can be altered by just removing the composite resin, and repositioning it mesially or distally without causing any distortion of the arch wire or the guide. The appropriate rectangle of the guide corresponding to the exact height of microimplant placement is selected on the periapical radiograph. The rectangles are numbered from 1 to 6 starting from the end tied to archwire. The pilot drill is performed with the guide in place using a round diamond bur attached to a contraangled handpiece of a micromotor. The size of rectangle is sufficient to allow for drilling through it along any desired angulation. Microimplant is driven in after disengaging the guide from archwire. Subsequently, its accurate placement is confirmed by taking an intraoral periapical radiograph.

\section{CASE REPORT}

An 18-year-old male patient, TM presented to the Department of Orthodontics, MGMDCH with a chief complaint of forwardly placed upper front teeth. The patient exhibited class I bimaxillary protrusion. On intraoral examination, the mandibular 1 st permanent molars were missing. Treatment planned was extraction of both maxillary 1st premolars and retraction of anteriors with critical anchorage using microimplants.

After initial leveling and alignment, 0.19" $\times 0.25 "$ stainless steel was placed in the maxillary arch. The site of microimplant placement was decided in the interdental region between the 2 nd premolar and 1 st molar. The microimplant placement guide was then placed over the archwire with the aforementioned method using composite resin (Fig. 2A). An intraoral periapical radiograph (IOPA) was taken to evaluate the positioning of the guide, which was found to be alright (Fig. 2B). The exact site of implant placement was observed to be in the 5th rectangle of the guide. Pilot drill was carried out without disengaging the guide (Fig. 2C). The guide was then disengaged from the archwire. The microimplant was manually driven in through the pilot hole. Placement accuracy was confirmed clinically and by taking an IOPA (Figs 2D and E). The guide was sterilized for subsequent use.

\section{DISCUSSION}

Creekmore and Eklund (1983) were the first orthodontists to suggest that a small metal screw could withstand a constant force of sufficient magnitude and duration to reposition an entire anterior maxillary dentition without becoming loose, painful, infected or pathologic. ${ }^{5}$ They can be placed in areas where natural anchorage or conventional orthodontic appliances are impractical, including edentulous spaces in the alveolus of either arch, palate, zygomatic process, retromolar regions and ramus.

Early reports on the success of TADs ranged from 60 to $85 \%$, although recent reports, using the latest TAD designs and placement techniques, have shown dramatically higher success rates. Still, it was noted that TADs seem to be more successful in the maxilla than in the mandible and in adults than in children.

Incorrect insertion technique has been identified as a primary cause of failure in implant dentistry. ${ }^{4}$ The placement of these implants between the roots of the teeth has been challenging, however, because of the limited space and the risk of root damage. ${ }^{6-11}$ Placement of a microimplant too close to a root can also result in insufficient bone remodeling around the screw and transmission of occlusal forces through the teeth to the screws, which can lead to implant failure. ${ }^{12}$

Several devices have been developed to provide threedimensional control of the microimplant placement, making the procedure safer and more accurate. ${ }^{13,14}$ But, these include complicated laboratory procedures and multiple appointments for the patient.

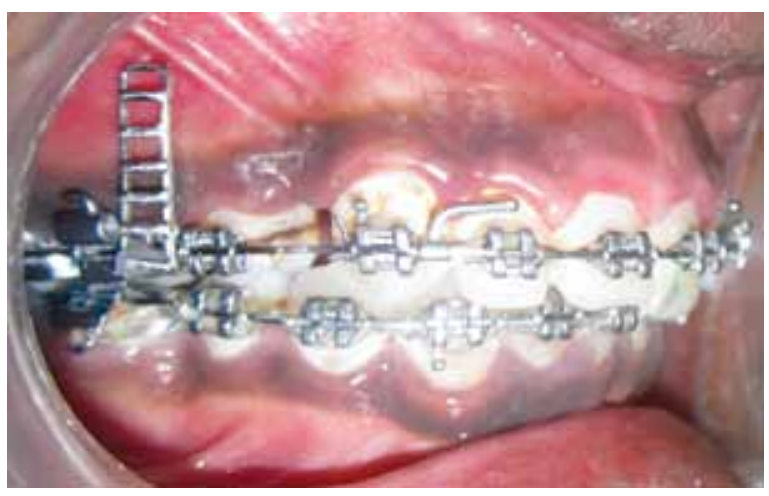

Fig. 2A: Microimplant placement guide secured to archwire 


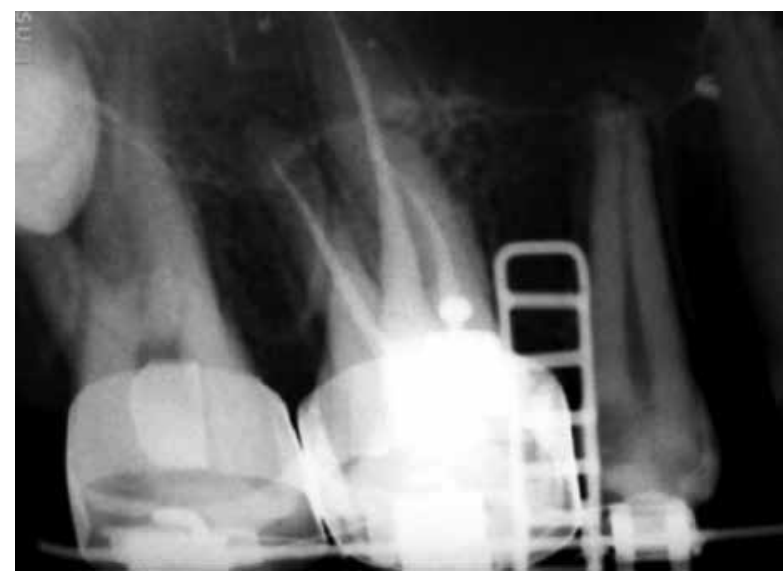

Fig. 2B: Periapical radiograph of the guide in place

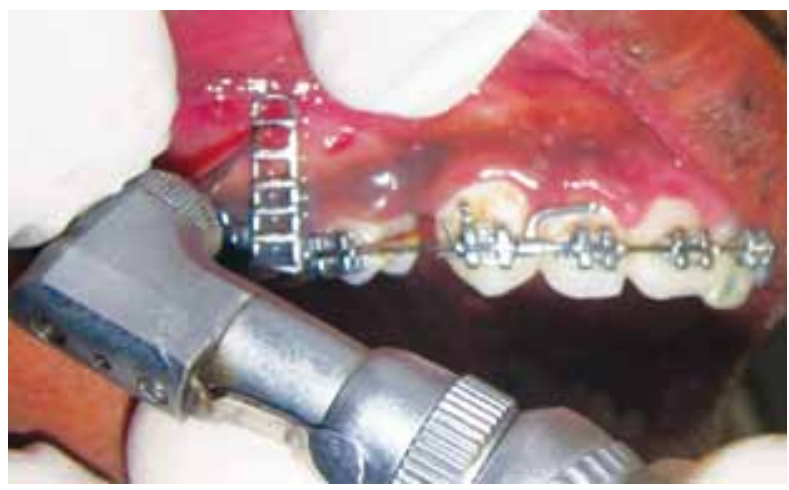

Fig. 2C: Pilot drilling in progress without disengaging the guide

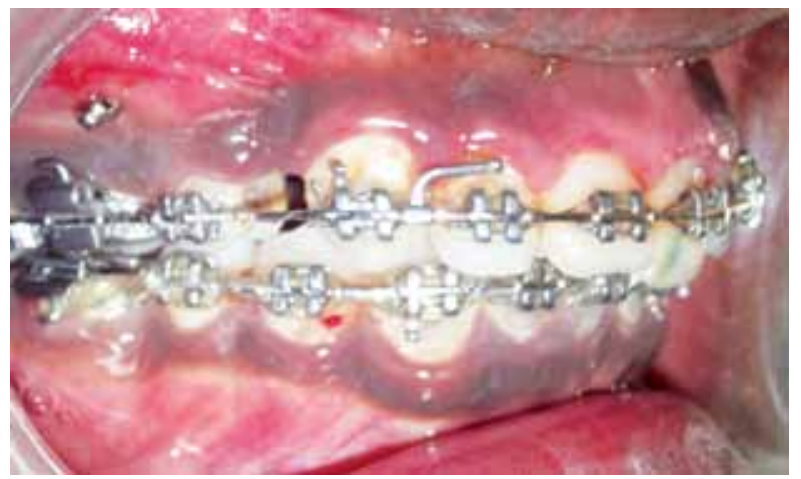

Fig. 2D: After microimplant placement

Thus, we have developed a metal microimplant placement guide that can improve the accuracy of microimplant placement in the anterior or posterior segments of either arch. The guide can be fabricated in various lengths so as to aid in microimplant placement in different regions of the oral cavity. The guide is easily attached to the archwire to determine the ideal microimplant position. This position can be altered effortlessly, if found to be faulty on the radiograph. The pilot drill can be carried out with the guide in place and it is then disengaged after drilling. The entire procedure does not require archwire removal; neither causes any deformation of either the archwire or the guide. Its

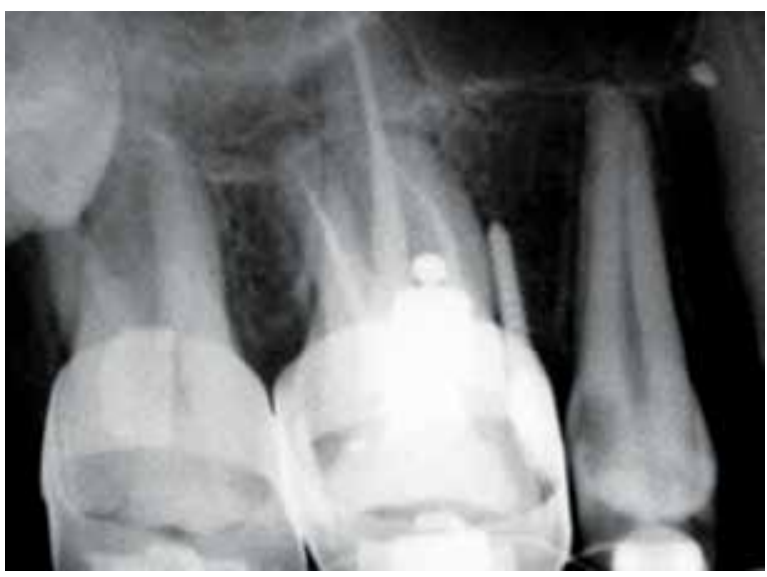

Fig. 2E: Periapical radiograph of the microimplant in its correct position

simple design permits easy fabrication, and the same device can be used for different patients following sterilization between uses.

Therefore, this design of microimplant placement guide can prove to be a simple yet efficient tool in assisting successful insertion of microimplants.

\section{REFERENCES}

1. Richard RJ. Cousley: a stent-guided mini-implant system. J Clin Orthod 2009;6:403-407.

2. Cousley RRJ, Parberry DJ. Surgical stents for accurate microimplant insertion. J Clin Orthod 2006;40:412-417.

3. Sung JH, Kyung, et al. Microimplants in Orthodontics, Dentos, Daegu, Korea 2006.

4. Ashley ET, Covington LL, Bishop BG, Breault LG. Ailing and failing endosseous dental implants: a literature review. J Contemp Dent Pract 2003;4:35-50.

5. Creekmore T, Eklund MK. The possibility of skeletal anchorage. J Clin Orthod 1983;17:266-269.

6. Bae SM, Park HS, Kyung HM, Kwon OW, Sung JH. Clinical application of microimplant anchorage. J Clin Orthod 2002;36: 298-302.

7. Carano A, Velo S, Leone P, Siciliani G. Clinical applications of the miniscrew anchorage system. J Clin Orthod 2005;39:9-24.

8. Lin JC, Liou EJ. A new bone screw for orthodontic anchorage. J Clin Orthod 2003;37:676-681.

9. Schnelle MA, Beck FM, Jaynes RM, Huja SS. A radiographic evaluation of the availability of bone for placement of miniscrews. Angle Orthod 2004;74:832-837.

10. Somchai M. Titanium mini-implant for orthodontic anchorage. J Thai Orthod 2004;3:41-46.

11. Kyung HM, Park HS, Bae SM, Sung JH, Kim IB. Development of orthodontic microimplants for intraoral anchorage. J Clin Orthod 2003;37:321-329.

12. Kuroda S, Yamada K, Deguchi T, Hashimoto T, Kyung HM, Takano-Yamamoto T. Root proximity is a major factor for screw failure in orthodontic anchorage. Am J Orthod 2007;131: S68-S73.

13. Jacobs R. Preoperative radiologic planning of implant surgery in compromised patients. Periodontol 2000, 2003;33:12-25.

14. Kopp KC, Koslow AH, Abdo OS. Predictable implant placement with a diagnostic/surgical template and advanced radiographic imaging. J Prosth Dent 2003;89:611-615. 